\title{
Perceptions of the cancer care left undone in primary and community services: a mixed methods evaluation
}

\begin{abstract}
Primary and community care in the United Kingdom are under increasing workforce and time pressures. How these pressures effect the delivery of cancer care has rarely been explored. This service evaluation aimed to elucidate some of the views of the workforce in this sector of what work in cancer care is left undone, and what they would like to be able to offer more of. An exploratory sequential design was taken including a questionnaire and interviews asking primary and community care staff in London about their workload in cancer care. Surveys were analysed using descriptive statistics. The evaluation revealed a perception from primary and community care that there is work in cancer care that is currently being left undone. $64 \%$ of the workforce across all professions reported that they worked 10 or more hours of unpaid overtime per week. Respondents identified psychological care for people with cancer, and bereavement care for families and carers of people with cancer as the most common areas that were left undone. They would like to do more proactive work, in place of the current reactive "fire-fighting" they are doing. For example, signposting available services to people with cancer and access to nutritional support. There was a desire for acknowledgement of the time and workforce pressures in primary and community care, and how these are hindering the delivery of care for people with cancer.
\end{abstract}

Keywords: cancer care, workload, workforce, primary health care, community care, workforce policy

\section{What is known about this topic}

- Workload of cancer care provision in primary and community care is well recognised, yet has rarely been explored.

\section{What this paper adds}


- This evaluation reveals some of the views of the workforce in this sector of what cancer care is left undone.

- $\quad$ Primary and community care staff would like to offer more support in psychological care, bereavement care and to be involved with more proactive cancer care.

- A foundation on which to base further research for improved cancer care delivery and coordination.

\section{Introduction}

The consequences of cancer and cancer treatment remain an understudied area of health care (Macmillan, 2013). However, the number of people in the United Kingdom (UK) living with and beyond cancer is increasing and is set to double from more than 2 million in 2010 to 4 million by 2030 (Macmillan, 2012). The role of primary and community care's workforce in caring for people during and after their cancer treatment is becoming well recognised, however, exactly what this role involves in practice is unclear (Hobbs et al., 2016). An improvement in the quality and availability of primary care data is needed in the UK, amongst other European countries (European Commission, 2018). Workforce challenges threaten primary and community care, and may result in shortages in care for people with cancer (PWC). There is evidence to suggest associations between care left undone in nursing and patient outcomes (Recio-Saucedo et al., 2017). This evaluation aimed to elucidate what work is currently left undone in caring for PWC in primary and community care.

Between 2006 and 2016, 34\% of all cancer diagnoses in England were from a two week wait referral and $26 \%$ were from an urgent or routine General Practitioner (GP) referral (NCRAS, 2016). As survivorship and end-of-life care become a greater focus of cancer care, primary and community care's part in this requires further definition. Long-term follow up for PWC is looking to be increasingly more primary care practitioners' role (Rubin et al., 2015). However, recent research has found that 
intensifying pressures on general practice have resulted in cuts in the number of routine appointments, and stress levels and burnout having consequences for patient care (Cogora, 2018). These consequences have not been studied in detail.

Moving care from hospitals to primary and community care has long been a policy goal for the National Health Service (NHS) (Department of Health, 2006). However, achieving this is reliant upon a stable workforce. The Kings Fund reported in 2018 "The workforce challenges in the NHS in England now present a greater threat to health services than the funding challenges." (Kings Fund, 2018). The number of nurses working in community health services and primary care in the UK has faced a long-term decline and has been identified as a key area of concern. Community trusts rank last among all NHS trusts in staff stability in England (Health foundation, 2019). The number of district nurses has declined by $45 \%$ since 2009 , and over the same time period the number of nurses in community services fell by $14 \%$ (Nuffield Trust, 2018). The number of GPs has fallen by $1.6 \%$ over September 2017 to September 2018. However, the number of general practice nurses has been expanding over recent years and there has been a small increase in advanced practice nurses and pharmacists based in general practice (Health Foundation, 2019). Workload in primary care has been described by NHS alliance as "undoable" ( $\mathrm{HCHC}, 2016)$. Gaining insight into the work that primary and community care staff do and cannot do is essential in understanding what these workforce shortages and gaps might mean for workload and delivery of care.

Evidently, primary and community services are understaffed, but what this, amongst a multitude of other factors means for the delivery of care for PWC is understudied. What work is being left undone, and which patients are being missed? This evaluation, as part of a larger study, aimed to gain insight into what work the healthcare professionals themselves believe is being left undone in cancer care. It explores where primary and community care identify challenges to delivering cancer care and potential reasons for these, and areas they would like to be able to do more. The hypothesis was that pressures in primary and community care are resulting in some cancer care being left undone. 'Care left undone' has previously been used interchangeably with 'missed care' and can refer to care either partially or 
fully omitted, due to a number of reasons (Ausserhofer et al., 2014; Ball et al., 2014; Ball et al., 2016).

\section{Methodology}

\section{Study Design}

This is an exploratory service evaluation that used mixed-methods (Bowling, 2014; Moule and Goodman, 2014). The initial views of the workforce were explored, before conducting a questionnaire and interviews. As part of a larger study of soft system modelling (an approach to organisational process modelling) (Checkland, 1989) of London cancer services, a focus group was carried out with primary health care professionals in London on their work with PWC. The focus group included GPs, and registered Nurses including practice nurses. This focus group, along with a review of the literature in the area exposed that workforce and time pressures meant there was a perception that work in cancer care was being left undone. This was the motivation for this evaluation.

A previously validated self-completed questionnaire was utilised to gain responses from a variety of roles in primary and community care (Leary et al., 2018; Stewart et al., 2018). The workload questionnaire was based on a previous evaluation of the work left undone in oncology nursing (Leary et al., 2013). It consisted of questions on caseload related to cancer, unpaid overtime, time for development and education, as well as free-text boxes on what care they would like to be able to offer and the challenges of delivering care to PWC. It was distributed through Health Education England's (HEE) weekly London newsletter over a six week period, which was sent by email to approximately three hundred recipients, clinical and non-clinical, and was accessed through an online link. Participants were invited to take part in the interview at the end of the questionnaire. Participant information sheets were provided to participants interested in interview, and informed consent was obtained by those that did take part. The interview guide is available in Box 1 .

Interviews (Feb 2019) were used to gain a deeper understanding of some of the respondents' views. The interviews were semi-structured interviews that were audio recorded and carried out by telephone by the first author (JL), as face-to-face 
meetings were harder to coordinate with practitioners' busy schedules. Interview duration was on average one hour. Interview questions covered participants' personal experiences and views of their involvement in cancer care, and sought to gain a deeper understanding of their experience. The interview guide was developed by two of the researchers and was internally reviewed and pilot tested. Interviews occurred after questionnaire completion, therefore respondents had the opportunity to reflect on their questionnaire responses in the interview. As interviews were carried out by telephone, field notes were made during interviews. This mixedmethods approach allowed for a deeper understanding of the respondents' views and opinions.

\section{Analysis}

The quantitative data from the questionnaire were summarised using descriptive statistics in Excel. Responses were compared across professional groups and only minor differences in viewpoints were found. Interviews were transcribed and Thematic Analysis (Braun and Clarke, 2006) was carried out to analyse transcripts using NVivoTM (Version 10, QSR International). Descriptive integration involved merging the quantitative and qualitative data to make comparisons and for deeper understandings to emerge. Methods triangulation ensured rigour and allowed for testing consistency in the different data sources (Patton, 1999).

\section{Ethics}

This was subjected to review from the NHS Ethical Committee Health Research Authority. It was reviewed proportionately and considered to be an evaluation.

Participants were provided with a participant information sheet prior to involvement, and written consent was obtained from all those who took part in both the questionnaire and interviews. Participation was voluntary and participants were reminded that they were free to withdraw at any point.

\section{Results}

The results of the questionnaire are presented alongside the interview data to allow for comparison. Interview responses allow depth and further detail to some questionnaire responses. The themes are broken down broadly into activities that 
are not able to be carried out, and challenges to cancer care delivery. Questionnaire quotes are presented in bold and interview quotes in italics to provide further clarity between the data.

\section{Questionnaire completion:}

The questionnaire was sent to an estimated 300 people. The questionnaire received 92 responses: response rate $=31 \%$ and completion rate $100 \%$.

A breakdown of respondents' roles and how long they had been working in primary or community care can be found in Tables 1-2. Ten or more completed questionnaires were received from the following professional groups: General Practitioner (Partner), General Practitioner (Salaried), District Nurse (SPQ), Advanced Nurse Practitioner.

\section{Interview completion:}

Seven interviews were carried out with two District Nurses (DN), one Advanced Nurse Practitioner (ANP), one Care Navigator, one GP (partner), one GP (salaried) and one GP (locum).

\section{Unpaid over time}

$97 \%$ of all professions answered that they worked unpaid overtime each week. $64 \%$ answered that they worked more than ten hours of unpaid overtime per week. Just $3 \%$ of respondents said they worked no unpaid overtime. Some $12 \%$ worked one to three hours, $16 \%$ worked four to seven hours and $4 \%$ worked eight to ten hours. GP Partners reported the highest level of working more than ten hours unpaid overtime per week at $80 \%$, and GP Salaried reported the lowest level at $50 \%$. A breakdown of all the professions' responses are in Table 3.

\section{Work not carried out}

\section{Continuing professional development}

Questionnaire respondents were asked about whether they had time for continuing professional development. 65\% (60) of respondents answered that they did have time for continuing professional development, while $21 \%$ (19) said that they did not. The remaining respondents selected "Other" (13) or that this was carried out in their free time and therefore unpaid. DNs were the profession that had the highest "No" 
response (to time for continuing professional development) at 35\%, and GPs (Partner) had the highest "Yes" response at 70\%.

When asked "If time and money were no object what educational or development opportunities would help you care for cancer patients in primary/community care?" the most popular questionnaire response from all professions were "Specialist study days" and "A specialist primary care cancer course" (Table 4).

\section{Additional services}

The questionnaire asked what additional services respondents would like to offer to PWC if money and time were no object. Offering a more joined-up approach with secondary care was desired, and some responses suggested the creation of a post to relay concerns or clear up miscommunications between primary and secondary care. There was a suggestion of cancer care support workers to accompany PWC from diagnosis through secondary and primary care.

Respondents identified a lack of and the need for patient peer support groups and suggested "open days" in community services for PWC to meet others. The same was suggested for families and carers of PWC.

"Group workshops, patients are often less anxious in a familiar setting. Care for the carers" - ANP

\section{"Psychological support for cancer patients and carers within primary care" - GP (Partner)}

These answers were reflected in the interviews. A lack of clarity for patients on who to contact during treatment was highlighted by an interviewed GP (salaried):

"Sometimes it's not very clear to patients who they should contact if they're having side effects from their cancer treatment, and sometimes it's not very clear to us either, what are the expected side effects. So that can be tricky." 
Advanced care planning was described as a substantial part of GPs' workload with PWC and was frequently being left too late. One GP (salaried) would like to see these conversations happening earlier and prior to hospice care involvement.

"I think we should be doing advanced care planning earlier with patients" GP (salaried)

The support that questionnaire respondents would like to see more of or to have more training in were psychological and mental health support, more tailored nutritional support, offering more exercise classes, pastoral care and further 24-hour services.

\section{"Counselling services or counselling training for nurses, we have great communication skills and ability to listen and support but sometimes feels inadequate" - DN}

$45 \%$ of respondents identified a wish to have more time to spend with PWC for investigating symptoms, supporting their family/carer needs and to provide counselling. Time limitations were restricting the provision of holistic care, which was something that they wished to provide.

\section{"Just more time to be more regularly supportive, and also to the families of affected patients" - GP (Partner)}

Answers revealed a need for building positive attitudes to living with cancer and offering a larger variety of treatments at home, such as a focus on personal care, and respiratory physiotherapy amongst a call for more tailored care at home. Respondents highlighted the need for improved financial support and ensuring comprehensive signposting of all available services.

As this questionnaire question received so many detailed responses, those that were interviewed were asked to delve deeper into this topic. In particular, two themes of psychological and bereavement care emerged. 


\section{Psychological care}

Psychological care and social care was an area that multiple interview respondents felt they were not doing enough in and would like to be able to offer more for PWC: "Psychological care it would probably be the same for both the cancer patients and not cancer patients, which is more care, the thing that is limiting us at the moment is social care." - Care Navigator

"Having social prescribing facilities within CCGs. Because, a lot of the stuff is not medical." - GP Partner

"Just trying to get them an appointment quickly to help them come to terms with their diagnosis or just somebody to talk to... I don't know where to refer them to." - ANP

Psychological care also extended to families, friends, and carers of PWC. An ANP talked of the difficulty of signposting people who were coming to terms with a recent cancer diagnosis.

"Some of them had a family member diagnosed as cancer but they were the main carer and they wanted the help. I just never knew where to signpost them to. I don't think that exists." - ANP

Furthermore, the GPs interviewed commented that after diagnosis, PWC require guidance in what support is available to them, but GPs are not always able to offer this, and these support services are variable.

"It's so variable from trust to trust. Some patients get a cancer nurse specialist, some get some psychology support.. some get nothing, have had zero support from anyone. Signposting...that takes the patients to be proactive, and when they've just had a diagnosis of cancer or going through cancer treatment it's very tough for them to be motivated to go to the centre, pick up the resources, read them and then proactively know where to go." - GP Locum

\section{Bereavement care}

Work associated with caring for the bereaved was reported varyingly in the interviews. All three GPs interviewed commented that there was no plan in place for 
bereavement (from any illness not just cancer). This meant GPs spent a lot of time locating available care that was difficult to find, or hard to access and meant that people sometimes went without bereavement care:

"There is no practice policy for that, that's just what individual GPs do." - GP

Salaried

"There is no set plan. Sometimes, I find I'm a bereavement counsellor GP, particularly if I know the patient well enough." - GP Partner

One GP reported: "We do have a commissioned bereavement service but they can't access it for six weeks, so for the first six weeks they are ours." - GP Locum

This was explained by six weeks of grieving being formally recognised as natural, and if after this time help is still needed, then a bereavement service would be offered to them.

Interviewed GPs felt as though they were offering bereavement and psychological care without having specific training on it, meaning that things could be missed.

"We spend a lot of our time providing psychological support when actually we're not experts in this" - GP Locum

A DN talked of constrained budgets and staffing shortages effecting bereavement care delivery:

"We do a general bereavement visit, just to see how they're coping. That's pretty much straightaway... not further down the line. At the minute, we've got a 'three visit' rule." - DN

\section{Challenges in cancer care delivery}

Questionnaire respondents were asked about the day-to-day challenges of caring for PWC, and how this affected workload. Time pressure was a frequent answer; there 
was not enough time in appointments to provide people with all the necessary information and making referrals and chasing up of results was time-consuming. Furthermore, time pressures meant that priorities were with supporting patients with "acute needs".

“To do it properly requires a lot of time which I just don't have day to day. It can leave you feeling that you have given suboptimal care to those who need it most." - GP (Partner)

"Difficult to give patients and families the time that they need and deserve" DN

The unpredictability of the work involved with cancer was reported to create large unanticipated and unplanned for workload, and delays in care for other patients.

"Can create a lot of unplanned work due to changing condition and speed of deterioration. Very rarely do visits go to plan" - DN

These themes was reflected in the interviews as well. One DN interviewed would like to see more allowances and understanding of the amount of time that is required to deliver safe, comprehensive care, and to account for the unpredictability of caring for PWC:

"Time is the biggest issue: so acknowledging that you're going into wound care but, actually, because it's a cancer patient, it may take a lot longer because they've got other issues going on. The acknowledgment that these visits...have more follow-up, whether that's admin stuff and onward referrals, or, once their wound's healed, they may need support afterwards."- DN

Obtaining and setting up care at home was reported as a challenge. Another interviewed DN reported that "It can actually be that people don't get the care until they've officially died." - DN

Two of the GPs interviewed reported that they would like to offer more proactive care rather than the current reactive care. One suggested that having more time would enable them to be more informed and prepared, and as a result, to deliver higher quality care. 
"I guess the long-term work that I do looking after our survivors I would say we're very reactive... and it would be nice to think that there was a service somewhere where those people had long-term follow up in the impact that their cancer had upon them." - GP Salaried

"I think that GPs are so overwhelmed and overworked being reactive to a system that is permanently on the urgent-urgent, because we're always trying to fix things that are broken with a little plaster that we don't get time to be proactive. We're firefighting."- GP Locum

Workforce pressures, capacity issues and resource limitations were also mentioned as challenges in questionnaire responses across the different professional groups, in particular understaffing.

\section{"We are under doctored." - GP (Partner)}

\section{"Short staffing and high complex patient volume" - DN}

This too was reflected in the interviews, where delivery of care was also described as dependent on having enough resources and capacity. A care navigator spoke of aiming for all services to be running at $80 \%$ capacity, so there is some leeway when there is high demand:

"When things go wrong or when people end up in the wrong places it's often because the right place was full. The problem is the systems are all so tight, you think the best thing is for them to come into the community hospital, but you haven't got any beds...because every last bed has been filled with somebody who's been shunted out from the main hospital." - Care Navigator

Being able to respond to crises at any time of the day and week was identified by an interviewee.

"We don't necessarily have to have everything seven days, but in terms of the ability to respond to a crisis you really need to have that to be seven days"- Care

\section{Navigator}


One challenge that was developed upon in the interviews was that of not being able to offer flexible care. Both DNs that were interviewed spoke of rigid structures that restricted finding and accessing appropriate care for PWC. They would like to see more flexibility in acceptance criteria for different services.

“(Patients that) 'Don't tick the boxes'. If you don't fit a box, it's extremely difficult. We're trying to provide the best care that we can possibly give. But there is just nowhere that you can go to... because everywhere has got their own acceptance criteria." - DN

An area where PWC seemed to be falling through the gaps due to rigid structures was nutrition. An ANP wanted to do more in this area, and to provide nutritional supplements for PWC, as this was currently not possible if they didn't meet requirements.

"I don't think their nutritional space is very well looked after. They're always having problems in getting supplements. If their weight's not less than whatever it's meant to be, then you can't get the nutritional supplements. Often, I find cancer patients saying that their appetite's reduced and they'd just like something to sip. But they can't get anything on prescription because they don't reach the requirements because their weight is fine but it is reducing." - ANP

\section{Discussion}

\section{Summary}

All professional groups identified areas where they would like to be providing improved or different care for PWC that they are currently not able to. From the questionnaire, $64 \%$ of all primary and community care professions answered that they worked more than ten hours of unpaid overtime per week, and 35\% did not have time for continuing professional development or carried this out in their own unpaid time. There is evidence in this evaluation to suggest that the primary and community care staff did not have enough time or specialised training to deliver the level of care they would like to for PWC. 


\section{Comparison with existing literature}

As an example, GP appointments with PWC would commonly overrun and delay other appointments. GPs reported planning appointments with PWC before lunch breaks or at the end of the working day to prevent these delays. This was largely put down to workforce pressures, appointment times being too short and the unpredictability of cancer care. This is concurrent with current research: the traditional model of ten-minute GP appointments in the UK do not allow the best possible care for patients (HCHC, 2016). There is significant and important work for PWC that is currently not being carried out by primary and community care: a demand is not being met (Kings Fund, 2019). It is well recognised that General Practice is under time pressures and there has been a recent push for reception and clerical staff to play a greater role in signposting to free up GP time (GP Forward view, 2016).

Caring for families and carers of PWC frequently came up as care that was left undone. This concurs with literature in this field: Macmillan (2013) reports that $67 \%$ of carers of PWC experience anxiety and $42 \%$ experience depression. Of these, over $75 \%$ do not receive any support, information or treatment. The majority of adults with mental health issues seek support primarily from primary care (Kings Fund, 2019). In this evaluation, lack of time and appropriate training were the main reasons for why they were delivering a level of care to this group that they were dissatisfied with. For all carers in the UK (not specific to PWC) their average quality of life score decreased from 8.1 to 7.7 (out of 12) between 2012-13 and 2016-17 (Nuffield Trust, 2019). This decline suggests a need for increased care for this group. Additionally, asking PWC what skills and information would be helpful for their families and carers to learn could help guide support for this group. There is an unmet demand from primary and community care that is likely to rise without interventions to increase staffing levels to enable individuals more time and training in this area. Furthermore, future research into 'care left undone' could be useful in determining whether this is care that is missed entirely, or care that is rushed, or not carried out to a high standard (Ball et al., 2014). Care left undone has the potential for moral conflict in staff, and the impact of care left done in PWC is understudied (Ausserhofer et al., 2014). 
As was brought up in the interviews, PWC didn't always fit the specific requirements for certain treatments, meaning that they could not access some care. Nutritional support is one example of where rigid structures in accessibility mean that PWC are perceived to be missing out on appropriate care. In Adams (2011) UK study, interviews with PWC in primary care revealed views that too much structure was a threat to individualised and tailored care. Calls for flexibility and less rigidity in access to care for PWC have been made.

\section{Implications for research and/or practice}

Bereavement care was revealed to be inaccessible for primary care to offer for the first six weeks of bereavement. This is clearly an area where people require care and are falling through the gaps: steps should be taken to address this group. Staff reported that as they had no set bereavement care plan in place (for people affected by the deaths of PWC, or any cause), they spent a significant amount of time searching for appropriate care for the bereaved. By having a set bereavement care plan, or a structured source of available resources, time could be saved for GPs (as one example). The findings suggest that training in bereavement and prebereavement care would be valuable for primary and community staff. Primary care physician skills in bereavement care have been identified as an area that is understudied in the literature, and an area that may warrant further research (Ghesquiere et al., 2014).

The need for more proactive care to take the place of the current reactive work was highlighted. The fact that obtaining care in the home for PWC sometimes did not happen until the person has died is a very revealing call for change.

\section{Strengths and Limitations}

A strength of this evaluation is that it reveals views and opinions of this workforce on cancer care that have not been previously explored. The results are not generalisable to other groups and purely provide insight and depth in to a selfselecting group of individuals in this evaluation's experiences of providing cancer care. Therefore, a limitation is that there is a risk of oversimplifying these views at this scale. The questionnaire results were compared across professional groups and 
not between groups as only minor differences in viewpoints were found. Sample size was also a contributing limiting factor to this. The questionnaire was distributed via HEE London region primary care weekly newsletter of 300 people. One professional association also distributed the link to the questionnaire through social media but it is not possible to gauge the reach.

The previously validated questionnaire that this evaluation was adapted from was for a nurse population.

\section{Conclusion}

This evaluation shows that this workforce perceives that there are areas of cancer care that are being left undone. The areas that primary and community care staff identified as lacking and needing to be addressed were having more time to be able to deliver the specialised required care, proactive care, psychological care, bereavement care and support for families and carers. Shortages in care for PWC in primary and community care are evident and workforce pressures are increasing. Steps to address these shortages are critical.

Ethical approval This was subjected to review from the NHS Ethical Committee Health Research Authority (HRA). It was reviewed proportionately and considered to be an evaluation.

1. Adams E, Boulton M, Rose P, Lund S, Richardson A, Wilson Sand Watson E. 2011. Views of cancer care reviews in primary care: a qualitative study British Journal General Practice; 61 (585): e173-e182. DOI:

https://doi.org/10.3399/bjgp11X567108 Available at https://bjgp.org/content/61/585/e173 [Accessed 17/4/2019] 
2. Ausserhofer D, Zander B, Busse R, et al. Prevalence, patterns and predictors of nursing care left undone in European hospitals: results from the multicountry cross-sectional RN4CAST study. BMJ Quality \& Safety 2014;23:126-135.

3. Ball J, Murrells T, Rafferty A, Morrow E, Griffiths P. 'Care left undone' during nursing shifts: associations with workload and perceived quality of care. BMJ Quality \& Safety 2014;23:116-125.

4. Ball, J, Griffiths, P, Rafferty, A, Lindqvist, R, Murrells, T \& Tishelman, C. A cross-sectional study of 'care left undone' on nursing shifts in hospitals. Journal of Advanced Nursing 2016; 72( 9), 2086- 2097. doi: 10.1111/jan.12976

5. Braun, V. and Clarke, V. 2006. Using thematic analysis in psychology. Qualitative Research in Psychology, 3 (2). pp. 77-101. ISSN 1478-0887

6. Bowling, A. 2014. Research methods in health: Investigating health and health services. $4^{\text {th }}$ Edition. Berkshire: Open University Press.

7. Buchan J, Charlesworth A, Gershlick B, Seccombe I. 2019. A critical moment. NHS staffing, trends, retention and attrition. Health Foundation report.. Available at https://www.health.org.uk/publications/reports/a-critical-moment [Accessed 19-2-19]

8. Checkland P. 1989. Soft systems methodology Human Systems Management, Vol. 8, pp. 273-283

9. Cogora. 2018. Primary Concerns. The State of Primary Care. Available at https://www.cogora.com/wpcontent/uploads/2019/03/Cogora State of Primary Care Report LR.pdf [Accessed 09-04-19]

10. Cohen, M. 1987. A historical overview of the phenomenological movement. Journal of Nursing Scholarship, 19(1), 31-34.

11. Department of Health. 2006. Our health, our care, our say: a new direction for community services.

12. European Commission. 2018. A NEW DRIVE FOR PRIMARY CARE IN EUROPE: RETHINKING THE ASSESSMENT TOOLS AND METHODOLOGIES Report of the Expert Group on Health Systems Performance Assessment 
13. General Practice Forward View, NHS England. 2016 Available at https://www.england.nhs.uk/wp-content/uploads/2016/04/gpfv.pdf [Accessed 18/04/19]

14. Ghesquiere AR, Patel SR, Kaplan DB, Bruce ML. 2014. Primary care providers' bereavement care practices: recommendations for research directions. International Journal of Geriatric Psychiatry. 29(12):1221-1229. doi:10.1002/gps.4157

15. Giorgi A, Giorgi B, Morley J. The Descriptive Phenomenological Psychological Method. Sage. Handbook of Qualitative Research, Willig and Staunton (eds) 2017 Chapter 11. 2017

16. HCHC House of Commons Health Committee. Primary care Fourth Report of Session 2015-16 Available at:

https://publications.parliament.uk/pa/cm201516/cmselect/cmhealth/408/408.p df [Accessed 09/04/19]

17. Hobbs R, Bankhead C, Mukhtar T, Stevens S, Perera-Salazar R, Holt T. Clinical workload in UK primary care: a retrospective analysis of 100 million consultations in England, 2007-14. The Lancet VOLUME 387, ISSUE 10035, P2270-2272, JUNE 04, 2016

18. Holloway I. Qualitative research in health care. McGraw-Hill Education (UK), 1 Jun 2005

https://www.kingsfund.org.uk/sites/default/files/2019-03/closing-the-gaphealth-care-workforce-full-report.pdf

19. Husserl, E. The crisis of European sciences and transcendental phenomenology (D. Carr, Trans). Evanston IL: Northwestern University Press. 1970

20. Leary A, White J, Yarnell L. The work left undone. Understanding the challenge of providing holistic lung cancer nursing care in the UK, European Journal of Oncology Nursing 2013, http://dx.doi.org/10.1016/j.ejon.2013.10.002

21. Leary A, Mason I, Punshon G. Modelling the Inflammatory Bowel Disease Specialist Nurse Workforce Standards by Determination of Optimum Caseloads in the UK. Journal of Crohns \& Colitis. 2018 Nov 15;12(11):12951301. doi: 10.1093/ecco-jcc/jjy106. 
22. Lopez K, Willis D. Descriptive Versus Interpretive Phenomenology: Their Contributions to Nursing Knowledge Qualitative Health Research 2004 Volume: 14 issue: 5 , page(s): 726-735

23. Macmillan People living with cancer. November 2012. Available at: https://www.macmillan.org.uk/ images/people-living-with-cancer tcm9283689.pdf

24. Macmillan Throwing light on the consequences of cancer and its treatment. 2013 Available at https://www.macmillan.org.uk/documents/be macmillan/mac15485-cotthrowing-the-light-report-pages-2015full.pdf? ga=2.135221745.1918040786.15508309311234529538.1538039969 [Accessed 22-2-19]

25. Morse J. Qualitative Nursing Research: A Contemporary Dialogue. SAGE Publications, 1990

26. Moule, P. and Goodman, M 2014. Nursing Research: An introduction. $2^{\text {nd }}$ Edition. London: SAGE

27. NCRAS. Routes to diagnosis publication. 2016 http://www.ncin.org.uk/publications/routes to diagnosis

28. Nuffield Trust. What's really going on with nursing outside hospital? 2018 Available at https://www.nuffieldtrust.org.uk/news-item/what-s-really-going-onwith-nursing-outside-hospital [Accessed 19-2-19]

29. Nuffield Trust. Carer reported quality of life. Quality Watch - Indicators. 2019 https://www.nuffieldtrust.org.uk/resource/carer-reported-quality-of-life

30. Patton M. Q. Enhancing the quality and credibility of qualitative analysis. Health services research, 1999. 34(5 Pt 2), 1189-1208.

31. Recio-Saucedo A, Dall'Ora C, Maruotti A, Ball J, Briggs J, Meredith P BSc, Redfern O, Kovacs C, Prytherch D, Smith G, Griffiths P. What impact does nursing care left undone have on patient outcomes? Review of the literature. Journal of Clinical Nursing 2017

32. Rubin G, Berendsen A, Crawford M, Dommett R, Earle C, Emery J, Fahey T, Grassi L, Grunfeld E, Gupta S, Hamilton W, Hiom S, Hunter D, Lyratzopoulos G, Macleod U, Mason R, Mitchell G, Neal R, Peake M, Roland M, Seifert B, Sisler J, Sussman J, Taplin S, Vedsted P, Voruganti T, Walter F, Wardle J, Watson E, Weller D, Wender R, Whelan J, Whitlock J, Wilkinson C, de Wit N, 
Zimmermann C. The expanding role of primary care in cancer control. The Lancet Oncology Commission. 2015 Vol 16

33. Stewart I, Leary A, Tod A, Borthwick D, Khakwani A, Hubbard R, Beckett P, Tata L. Barriers to delivering advanced cancer nursing: A workload analysis of specialist nurse practice linked to the English National Lung Cancer Audit. European Journal of Oncology Nursing. 2018 Oct;36:103-111. doi: 10.1016/j.ejon.2018.07.006.

34. The Kings Fund Closing the gap: Health care workforce 2019

35. The Kings Fund.. The health care workforce in England: make or break? 2018 Available at https://www.kingsfund.org.uk/publications/health-care-workforceengland [Accessed 19-2-19]

36. Vaismoradi $\mathrm{M}$, Turunen $\mathrm{H}$, Bondas $\mathrm{T}$ Content analysis and thematic analysis: Implications for conducting a qualitative descriptive study. Nursing and Health Sciences. 2013 
Tables

Table 1. Questionnaire respondents

\begin{tabular}{lll}
\hline What is your role? & Number & Percentage \\
\hline General Practitioner (trainee) & 1 & $1 \%$ \\
\hline Care Navigator & 2 & $2 \%$ \\
\hline Clerical \& Admin staff & 2 & $2 \%$ \\
\hline Health Care Assistant & 2 & $2 \%$ \\
\hline Practice Nurse & 4 & $4 \%$ \\
\hline Community Nurse & 5 & $5 \%$ \\
\hline Other & 7 & $8 \%$ \\
\hline General Practitioner (salaried) & 10 & $11 \%$ \\
\hline District Nurse (SPQ) & 17 & $18 \%$ \\
\hline General Practitioner (partner) & 20 & $22 \%$ \\
\hline Advanced Nurse Practitioner & 22 & $24 \%$ \\
\hline Total & $\mathbf{9 2}$ & $\mathbf{1 0 0}$ \\
\hline
\end{tabular}


Table 1.1. Questionnaire "Other" Respondents

\begin{tabular}{ll}
\hline Role: Other (please specify) & Number \\
\hline $\begin{array}{l}\text { Advanced Clinical } \\
\text { Practitioner (Trainee) }\end{array}$ & 1 \\
\hline Cancer primary care nurse & 1 \\
\hline $\begin{array}{l}\text { Clinical Learning and } \\
\text { Development Lead }\end{array}$ & 1 \\
\hline Community Matron & 1 \\
\hline Locum GP & 2 \\
\hline Portfolio GP & 1 \\
\hline Total & $\mathbf{7}$ \\
\hline
\end{tabular}


Table 2. Years worked in primary or community care

\begin{tabular}{lll}
\hline $\begin{array}{l}\text { How long have you been working in } \\
\text { primary/community care? }\end{array}$ & Count & Percentage \\
\hline Less than $\mathbf{1}$ year & 3 & $3 \%$ \\
\hline $\mathbf{1}$ to $\mathbf{3}$ years & 5 & $5 \%$ \\
\hline $\mathbf{4}$ to $\mathbf{5}$ years & 11 & $12 \%$ \\
\hline $\mathbf{6}$ to $\mathbf{1 0}$ years & 15 & $16 \%$ \\
\hline $\mathbf{1 1}$ to $\mathbf{1 5}$ years & 24 & $26 \%$ \\
\hline $\mathbf{1 6}$ to $\mathbf{2 0}$ years & 14 & $15 \%$ \\
\hline More Than 20 years & 20 & $22 \%$ \\
\hline
\end{tabular}


Table 3. Hours of unpaid overtime per week

\begin{tabular}{llllll}
\hline $\begin{array}{l}\text { Hours of } \\
\text { unpaid } \\
\text { overtime per } \\
\text { week }\end{array}$ & None & $\mathbf{1 - 3}$ & $\mathbf{4 - 7}$ & $\mathbf{8 - 1 0}$ & $\mathbf{1 0 +}$ \\
\hline All & $3 \%$ & $12 \%$ & $16 \%$ & $4 \%$ & $64 \%$ \\
professions & $\mathrm{n}=3$ & $\mathrm{n}=11$ & $\mathrm{n}=15$ & $\mathrm{n}=4$ & $\mathrm{n}=59$ \\
\hline GP & $0 \%$ & $40 \%$ & $10 \%$ & $0 \%$ & $50 \%$ \\
(Salaried) & $\mathrm{n}=0$ & $\mathrm{n}=4$ & $\mathrm{n}=1$ & $\mathrm{n}=0$ & $\mathrm{n}=5$ \\
\hline GP (Partner) & $0 \%$ & $5 \%$ & $10 \%$ & $5 \%$ & $80 \%$ \\
& $\mathrm{n}=0$ & $\mathrm{n}=1$ & $\mathrm{n}=2$ & $\mathrm{n}=1$ & $\mathrm{n}=16$ \\
\hline ANP & $0 \%$ & $14 \%$ & $9 \%$ & $0 \%$ & $77 \%$ \\
& $\mathrm{n}=0$ & $\mathrm{n}=3$ & $\mathrm{n}=2$ & $\mathrm{n}=0$ & $\mathrm{n}=17$ \\
\hline DN & $0 \%$ & $0 \%$ & $29 \%$ & $12 \%$ & $59 \%$ \\
& $\mathrm{n}=0$ & $\mathrm{n}=0$ & $\mathrm{n}=5$ & $\mathrm{n}=2$ & $\mathrm{n}=10$ \\
\hline
\end{tabular}


Table 4. Educational and development opportunities

\begin{tabular}{lll}
\hline $\begin{array}{l}\text { If time and money were no object what educational or } \\
\text { development opportunities would help you care for } \\
\text { cancer patients in primary/community care? }\end{array}$ & Count & Percentage \\
\hline Specialist study days & 72 & $26 \%$ \\
\hline Shadowing acute specialist cancer colleagues & 47 & $17 \%$ \\
\hline Post Registration education short courses & 48 & $17 \%$ \\
\hline Physical assessment & 20 & $7 \%$ \\
\hline Masters degrees/modules & 21 & $7 \%$ \\
\hline $\begin{array}{l}\text { Course leading to registration (if not already a registered } \\
\text { healthcare professional) }\end{array}$ & 6 & $2 \%$ \\
\hline Specialist professional qualifications i.e. SPQ & 12 & $4 \%$ \\
\hline A specialist primary care cancer course & 55 & $20 \%$ \\
\hline
\end{tabular}


Box 1. Interview guide: Perceptions of the cancer care left undone in primary and community services

1. Can you tell me about the type of work you do for people with cancer?

2. If you can recall your workload last week on a particular day, were you in contact with a person with cancer?

3. Is there any of your work you think goes unrecorded or unrecognised?

4. Are you involved in work to do with preventing cancers and risks of cancers?

5. If time and money was no object what work would you like to be doing in cancer care that you are not able to do now? 